\title{
Enhancing Pre-schoolers' Reasoning Skills: An Intervention to Optimise the Use of Justificatory Speech Acts During Peer Interaction
}

\author{
Donna McWilliam and Christine Howe \\ Department of Psychology, University of Strathclyde
}

It has long been acknowledged that justificatory speech is linked with both social and cognitive development. Yet many studies suggest that pre-school children might lack the ability or experience to produce such discourse in routine interaction. In contrast, researchers such as Eisenberg and Garvey (1981) have found evidence of pre-schoolers' justifications in conflictual play contexts. Although this has positive implications for child development, the conflictual context may sit uneasily with parents' and teachers' expectations. It is encouraging therefore that McWilliam (1999) has demonstrated that pre-schoolers can produce justificatory dialogue in both conflictual and nonconflictual situations, even if occurrence in the latter context is less frequent. Based on this, the aim of the present study was to encourage pre-schoolers' production of justificatory discourse during peer exchanges in a non-conflictual context. Twenty-two dyads from a state-run nursery were subject to verbal modelling of either justificatory speech (experimental condition) or a more commonly used alternative (control condition) in daily ten-minute sessions over five consecutive days. All interactions were videorecorded for subsequent coding and analysis. Results showed that both 'why' questions and 'justifications' were significantly higher in the experimental condition, indicating that pre-schoolers' explanatory speech can be effectively enhanced by a cooperative intervention programme.

Keywords: pre-schoolers, intervention, reasoning, justification, interaction

Reasoning skills involve a degree of perspective-taking which can be explicitly demonstrated during peer interaction by: (a) giving and asking for justifications - these are reasons, explanations or why-questions produced or elicited to excuse, account for or clarify participants' verbal or non-verbal behaviour; (b) weighing up different sides of an argument, and (c) offering compromises or alternatives (suggested through speech or accompanying action) in appropriate situations. However, owing to the very young age of the children involved in this study and to information gained from previous piloting, the authors decided to focus primarily on enhancing the reasoning skills characterised by the speech acts outlined in point (a) (McWilliam, 1999).

\section{Introduction}

There is consensus among those interested in development and learning that skilful discussion is important for social and cognitive growth (e.g. Bruffee, 1984; Schober-Peterson \& Johnson, 1989; Tolmie \& Howe, 1993). Although Meadows (1986) has highlighted the difficulty of defining precisely what such skill 
involves, many researchers and educationalists believe that truly skilful speech can be characterised by evidence of reasoning. For example, Berkowitz et al. (1980) and Kruger (1993) have proposed that reasoning behaviour (and particularly seeking clarification and giving justification) is reflective of superior conceptual and perspective-taking abilities.

Educational guidelines also acknowledge the importance of children's discussion skills, with the Scottish Office Education Department's (1991) English Language 5-14 proposing that skilful discussion should consist of elaboration, clarification and justification. Likewise, the Department for Education (1995: 11) states that key discussion skills should include 'qualifying or justifying'. On the social side, effective discussion skills are often required in everyday communication. For example, Charlesworth (1996) and LaFreniere (1996) both stressed the importance of reasoning through discussion to obtain personal or group objectives and to compete for increasingly unequal resources in modern society. Indeed, a lack of the requisite abilities can have adverse social implications from a very early age, with Walker et al. (1994: 74) claiming that children with poor discussion strategies 'are likely to be neglected and/or rejected by their peers'.

It therefore seems particularly important to ensure that, from the earliest stages, children have a sound grasp of how to reason during the course of discussion. Nevertheless, although researchers and educationalists would generally accept this, opinion is divided over the age at which reasoned discussion is effectively deployed. As early as 1926, Piaget acknowledged the importance of justificatory dialogue between peers, and claimed that he had seen little evidence of this in children younger than eight years of age. Educational guidelines tend to be more conservative, with the English Language 5-14 (Scottish Office Education Department, 1991) suggesting that reasoned discussion is unlikely in children under 11 or 12 years old.

It is therefore unsurprising that most empirical research has concentrated on older children in formal classroom settings. Indeed, insofar as research in these settings has been conducted with younger children, the results are often unpromising. O'Donnell and Dansereau (1992) stated that co-operation between young children is rare, whilst Baines (1996) reported that five-year-olds are poor both at co-operating and at producing cohesive discourse. Cooper and Cooper (1984: 81) found that kindergarteners often fail to negotiate adequately with their peers and suggested 'their ability to give explanations is flawed in many ways'. Similarly, Azmitia (1988: 88) stated that pre-schoolers are unable to 'sustain discussions . . . assumed to mediate learning' whilst Cazden (1986) noted that young children rarely ask questions of clarification. If the latter is true, it has clear educational implications. Indeed, King and Rosenshine (1993:123) strongly advocate the need for direct questions to 'elicit explanations that, in turn, mediate learning'.

In contrast, Eisenberg and Garvey (1981) demonstrated that pre-school children can effectively use justifications, ask for explanations and give alternatives during dyadic confict in a laboratory playroom. Orsolini (1993: 283) concurred with this finding and stated that within a conflict situation 'justifications are expected moves. When speakers do not produce them, the recipient is very likely to ask for an explanation'. Likewise, Baines (1996: 166) noted that although justifications were rare in four-year-olds, the ones that did occur were produced 'in a 
dispute setting'. Further evidence for the importance of disputes as a context that supports and enhances pre-school reasoning comes from work by Iskander $e t$ al. (1995) plus Vespo et al. (1995). Taken together, such findings indicate that reasoning through discussion (albeit conflictual discussion) emerges at a much earlier age than once thought.

Nevertheless, there is an important issue that needs to be addressed. Even if reasoning is more prevalent during conflictual discussion, disputes are unlikely to be encouraged either at home or in the classroom. Additionally, although associated with socio-cognitive development, it might be deemed unethical to use this context in order to enhance children's reasoning skills. This is especially the case given that Howe et al. (2000: 7) reported that 'disputes were considerably more aggressive than non-conflictual interaction'. Moreover, it has been suggested that disputes can be both triggered by relatively aggressive children and be instrumental in drawing out aggression from children regardless of their inherent characteristics (e.g. Arsenio \& Lover, 1997; Calkins et al., 1999). Reflecting this, conflict tends to be viewed in a rather negative light by parents and teachers, with documents such as Partners in Learning (Strathclyde Regional Council, 1994) emphasising the value of co-operation and interpersonal skills in education.

In fact, co-operative activities have long been perceived as beneficial to education and learning (e.g. Cooper et al., 1982; Howe, 1997) and therefore it may be pertinent that Kruger (1993) has argued that co-operation is just as likely as conflict to promote socio-cognitive development if the exchanges involve a process of reasoning. In addition, co-operation generally tends to be more widespread than conflict, with Howe, McWilliam and Bermejo Bravo (2000) reporting that non-conflictual exchanges outnumber conflictual by a ratio of around 3 to 1 . Nevertheless, there is little clear-cut evidence showing that co-operative discussion is conducive to reasoning.

However, observations made by McWilliam (1999) of pre-schoolers engaged in conflictual and non-conflictual peer exchanges during free play demonstrated that a degree of justificatory dialogue was produced in both contexts. During disputes, the children produced justificatory speech patterns in line with those found by Eisenberg and Garvey (1981). In the non-conflictual context, the most commonly used speech sequence was a 'claim' speech act followed by a general question (such as what, where or when) then a non-justificatory response. Similarly, but less frequently in this context, the pre-schoolers produced sequences of 'claim' followed by a 'why' question and a 'justification'. This evidence of reasoning in a non-conflictual context is encouraging because it shows that pre-schoolers are capable of engaging in the relevant form of discussion. It suggests, therefore, that an intervention might be possible to boost the frequency to the levels observed during conflict. As a result, the important question arises about what type of intervention would optimise reasoning in non-conflictual interaction.

In addressing this question, the theoretical tenets of Vygotsky (1962) and Bruner (1978) can be drawn upon. These authors believed that any intervention should involve the degree of scaffolding suited to a child's individual needs, with many scaffolding procedures involving the main phases of direct verbal instruction, modelling of required behaviour and withdrawal of support (e.g. Cole, 1986). This type of approach is perceived to be particularly beneficial in 
developing aspects of language use (e.g. Kirchner, 1991; McTear, 1985; Mentis, 1994), with Levy et al. (1992) suggesting that dialogue could be scaffolded through role-play - running through a sequence of greatest support to no support by the end of the intervention period. However, some caution may be required when designing such a programme since Baines (1996) noted that overly structured interactions can lead to poor child responses, thereby suggesting that any intervention should be semi-structured.

Although one must be aware of the importance of sensitive scaffolding, other factors relating to optimal performance should also be considered. For example, Donaldson (1978) suggested that emotion, self-interest and meaningfulness might be prime motivators in learning. This could, in part, explain why conflict contexts are more conducive to reasoning sequences than non-conflict contexts. Type of play activity also appears to be linked to language skill, with Howe and McWilliam (2001) demonstrating that both construction and symbolic play were associated with the production of a greater number of explanatory exchanges. Whilst symbolic play, fantasy and role-play have frequently been linked to enhanced reasoning or justificatory skills (e.g. Goncu, 1993; Smilansky, 1968), novelty toys or tasks have led to ambiguous reports. Cooper and Cooper (1984) argued that novelty would inhibit children's explanations because they do not have the relevant experience to draw upon to make sense of the novel situation. In contrast, Jensen (1968) believed that novel play materials could aid language development because participants would have to elaborate and extend their present knowledge to fit the new circumstances. McWilliam (1999) introduced pre-schoolers to a novel beetle task and found that this activity tended to elicit a relatively high frequency of 'why' questions - with some of these followed by 'justifications'. Indeed, Webb (1982) suggested that explanations were most useful in new contexts and not necessarily beneficial (or expected) in situations that are already familiar.

Bearing the above points in mind, a five-day, semi-structured intervention programme based on symbolic play was designed and implemented. An alien theme was followed, with storylines being introduced by the researcher. These storylines had elements of both familiarity (e.g. hospital sub-theme) and novelty (e.g spaceship crashing into a star) and could be adopted or extended by the children. 'Alien' puppets modelled either 'justificatory' or 'non-justificatory' three-turn speech sequences to dyads in 10-minute play sessions. Researcher support was decreased over the period of intervention, with children totally unsupported on Day 5. The purpose of the study was: (a) to collect information regarding the impact on pre-schoolers' justificatory skills; (b) to evaluate the efficacy of the intervention programme, and (c) to consider practical implications arising from the findings.

\section{Method}

\section{Design}

As reported above, pre-school children demonstrate some ability to produce justificatory speech, but such speech tends to be infrequent in non-conflictual exchanges. Therefore, it may be argued that pre-schoolers do possess relevant 
linguistic abilities, but lack a framework for displaying these outside of conflicts. Both Vygotsky (1962) and Bruner (1978) highlighted the importance of support or scaffolding by more capable others in order to extend already present but underdeveloped skills, and this was acknowledged in the present study. However, it was also noted that an overly formal or meaningless framework might have an adverse effect on children's performance (e.g. Baines, 1996; Fey, 1988). Thus, the approach also took account of children's own interest whilst maintaining a focus on the required language skills.

As previously noted, studies by Howe and McWilliam (2001) and McWilliam (1999) demonstrated that symbolic play is associated with an increased production of speech acts and, in particular, justificatory speech. In addition, research using puppets in symbolic play has met with a considerable degree of success (Read \& Cherry, 1978; Swiezy et al., 1992), with pre-schoolers enthusiastically engaging in dialogue with the puppets. Given the fascination with robots, monsters and spaceships found in McWilliam's (1999) studies, it was thought that an 'alien' theme might be appropriate for a contemporary intervention scheme. To add salience to the programme, children were informed that the aliens' speech was limited and it was their remit to help them.

Hence, alien puppets were introduced to model the relevant language in each of two conditions. The verbal modelling for the control group focused on 'claims' followed by general questions and answers, whereas the verbal modelling for the experimental group comprised of 'claims' followed by 'why' questions and 'justifications' - the aim, of course, being to show that even pre-school children can effectively learn to produce justificatory strategies.

\section{Participants}

Originally, 56 pre-schoolers from a state-run nursery school on the outskirts of Glasgow were randomly selected to take part in the study with sex combinations of pairs matched across conditions. However, owing to subsequent absenteeism, only 44 children were present across the total intervention period and will be the focus of this paper. There were 30 boys and 14 girls remaining in the sample (reflecting the gender balance in the school as a whole), and all were of white ethnic origin. Eleven pairs of pre-schoolers, who attended nursery for morning sessions, were allocated to the control group (mean age $=53.27$ months, $\mathrm{SD}=$ 2.06) whilst 11 pairs of afternoon attendees made up the experimental condition (mean age $=54.36$ months, $\mathrm{SD}=2.24$ ). Although McGrew (1972) observed some differences in pre-schoolers' behaviour throughout the course of their day and attributed these to internal rhythms, Luce (1973) stresses that such rhythms will be overridden by exposure to familiar routines. She also notes that pre-schoolers tend to have 35-minute cycles of attentiveness/inattentiveness rather than a morning/afternoon variation. It was felt, then, that any confound from using morning/afternoon attendees for different conditions was weak (or, at least, unreliable) and would be far outweighed by the advantages of keeping the control group and experimental group separate. Moreover, it was confirmed that children were not assigned by the Local Education Authority to morning or afternoon sessions on the basis of either socio-economic status or any academic criteria, thus the case for equivalence across the two groups is strengthened. 


\section{Materials}

Alien-themed materials were introduced from the first day. Background information was supplied via an alien-based story and picture books. Posters plus stickers of spaceships and planets were also shown to stimulate interest. All materials were colourful, non-threatening and meant specifically for young children. Additionally, verbal modelling sessions made use of three puppets and a spaceship. Two of these puppets had a bright, furry appearance. The third puppet had velcro facial features, hair and limbs which the pre-schoolers could attach or detach as they wished. The spaceship was discoid-shaped, and 'beeped' and lit up when pressed. Children could also introduce 'props' themselves (e.g. toy food from the home corner) to enhance any interaction.

\section{Verbal modelling schedules}

Prior to the study, a set of dialogue sequences relevant to each condition had been prepared and piloted. For the experimental condition, the dialogue to be modelled followed a justificatory speech pattern consisting of 'claim-whyjustification' turn-taking sequences, e.g:

(1) A: I am an alien.

B: Why?

A: Because I come from another planet.

(2) A: I like this school.

B: Why do you like it?

A: Because I can talk to all the nice children.

For the control condition, the pattern to be modelled and reinforced was based on a turn-taking sequence of 'claim-question-response' such as:

(3) A: I am an alien.

B: Where from?

A: From another planet.

(4) A: I like this school.

B: What do you like about it?

A: I like to talk to the nice children.

\section{Procedure}

The intervention scheme consisted of daily 10-minute sessions over five consecutive days, with all exchanges taking place in a relatively quiet, demarcated area of the nursery school. Participants sat on floor cushions with the camcorder set-up in a convenient and safe corner of the play area, a couple of metres away. All sessions were video-recorded for later use.

On the first day, the experimental and control groups were treated identically - both being introduced to background information about aliens. Each group was divided into two subgroups of seven children for the purpose of receiving the general information. Each of the four subgroups (i.e. two experimental and two control) was then shown pictures of aliens, planets and spaceships, and read a thematically related story. Child participation was encouraged 
by posing such questions as 'Does anyone know where aliens live?', 'Does anyone know what an alien might look like?' and so on. The groups responded enthusiastically and, at the end of the session, were introduced to 'Zig' and 'Zag' - the two furry puppets. Each group was informed that Zig and Zag were aliens who could not speak our language very well. The children were asked if they would talk to the 'aliens' in the following days to help them with their speech and they eagerly agreed. The researcher then gave the pre-schoolers the opportunity to touch and hold the puppets before saying goodbye.

Days 2 to 4 focused on role-play and development of a storyline that would engage the children in exchanges involving the puppets and / or each other. After the initial sessions, where group activity was deemed necessary to maximise engagement with the materials, the subsequent sessions (i.e. sessions 2 through to 5) were conducted with the children in pairs. Initially, equal numbers of each sex combination had been chosen across conditions but, owing to some absenteeism during the intervention period, these numbers became unequal, resulting in seven male-only, one female-only plus three mixed pairs (control group), and five male-only, three female-only and three mixed pairs (experimental condition) being involved on all five days. Pairs were chosen for these sessions because the focus was on alternate turn-taking in three-part sequences, with only two main puppets being provided. The researcher used the puppets to model the speech patterns appropriate to each condition, with heaviest scaffolding being given on Day 2. At this stage, children were given direct instruction before the relevant speech was modelled. To instruct the pre-schoolers in each condition, the researcher first reminded them of the aliens' limited knowledge of English. She informed those child pairs in the control condition that the aliens could only say and understand sentences beginning with ' $I$ '. They were also told that the puppets could ask or answer any type of question. Each child pair in the experimental condition was informed that the aliens could understand and emit phrases starting with 'I' and could only comprehend questions beginning with 'why' and responses beginning with 'because'. The researcher gave examples of the appropriate speech patterns, and obtained confirmation from the children that they understood before proceeding. The researcher then used the verbal modelling schedules for each condition with the degree of input decreasing over successive days.

\section{Verbal modelling of required speech on Day 2}

At the beginning of Day 2's session, the researcher modelled the required language by speaking directly to either Zig or Zag and getting them to respond in the expected manner. She then manipulated both puppets as if they were speaking to each other. When the pre-schoolers appeared to understand the sequence of dialogue (e.g. by interrupting with a correct speech act after listening for a while), the researcher used the puppets to speak directly to the children. The child pairs were encouraged to respond in the required manner by the use of repetition, reinforcement, prompts, praise and feedback given by the researcher throughout the session. To facilitate the learning process, the researcher began with two-turn sequences before moving on to the three-step patterns. By the end of this session, pre-schoolers were able to produce the following: 
Control condition

(5)
Zag (researcher):
I like your dress.
Child:
What's that you've got on?
Zag (researcher):
That's my furry coat.

(6) Zag (researcher):

I'm hungry.

Child A:

Child B:

Haven't you got any sweets?

No, but he can have my dinner.

Experimental condition

(7) Zag (researcher):

Child:

I like your dress.

Why do you like it?

Zag (researcher): Because it's a nice colour.

(8) Zag (researcher): $\quad I^{\prime} m$ hungry.

Child A:

Child B:

Why are you hungry?

'cos he didn't have any dinner.

\section{Verbal modelling of required speech on Day 3}

The aim of Day 3's session was to transfer the balance of dialogue from the researcher to the children. The children were given a puppet each and encouraged to talk to each other - either directly or via the puppets. When silence ensued, the researcher prompted the child pairs by giving directions, e.g. 'Get Zig to ask why' or 'Tell Zag to answer the question'. Earlier piloting had revealed that lack of ideas, rather than linguistic deficits, were responsible for gaps in turn-taking, thus a spaceship and a third puppet called 'Spid' were introduced. The fact that this latest alien had detachable facial features and limbs led to substantially elaborated storylines, e.g:

Control condition

(9)
Child A (Spid):
I'm hurt.
Child B (Zig):
Do you want a plaster?
Child A (Spid):
Put it on my head.

Experimental condition

(10)
Child A (Spid):
Child B (Zig):
I'm hurt.
Child A (Spid):
Why are you hurt?
'cos the spaceship hit a star and we crashed.

\section{Verbal modelling of required speech on Day 4}

On Day 4, child pairs in both conditions were encouraged to engage in further role-play and dialogue with the puppets. The researcher kept her input to a minimum but continued to prompt, praise and offer feedback, where necessary. Discourse at this stage tended to be longer and more fluent, e.g:

Control condition

(11) Zig:

Oh poor Spid. 
Spid: $\quad I^{\prime} m$ hurt, I'm hurt.

Zig: Where's your arm?

Spid: That's it over there.

Zig: $\quad$ I can stick it back on.

Spid: $\quad$ Do you know where it goes?

Zig: There.

\section{Experimental condition}

(12) Spid: $\quad I$ hurt here.

Zag: Why?

Spid: 'cos that leg is missing.

Zag: $\quad$ I'll give you some medicine.

Spid: Why must I get medicine?

Zag: $\quad$ Because it'll make you better.

\section{Spontaneous production of speech on Day 5}

On the fifth and final day of the intervention programme, the researcher left the materials with the children and asked them to talk with the puppets as they had on previous days. This day was particularly important because there was no support available from the researcher, allowing examination of the intervention's sustained effects, a central issue when evaluating its success. At the start of this session the pre-schoolers were asked to recall what they had done the day before. Gentle reminders were given if necessary but most child pairs were aware of the requirements, e.g:

Experimental condition

(13) Researcher: Can you remember what we were doing yesterday with Zig, Zag and Spid?

JO: $\quad$ Yes, we were helping them to speak.

Researcher: What were you saying to them?

JO: $\quad$ I . . . I and 'cos.

Researcher: Anything else?

SA: WHY, I, 'cos and why.

The researcher then left the children to converse with each other (with or without the puppets, as they wished). She moved some distance away and only returned at the end of the 10-minute session to thank the child pairs and label the videotapes in preparation for subsequent transcription, coding and analysis.

\section{Transcription and coding}

Rather than analysing all the exchanges, it was decided to focus on: (a) Day 2, because that marked the beginning of verbal modelling; (b) Day 4, because this was the day before the dyads were left unsupported, and (c) Day 5, because that involved dialogue without intervention from the researcher. Simplified by input from the researcher, it was possible to code the Day 2 and Day 4 dialogue directly from the video-recordings and without transcription.The final intervention session was fully transcribed because it consisted wholly of peer discourse and 
therefore of dialogue that was completely new to the researcher. Coding focused on the frequency of the separate speech acts of 'claims', 'why questions' and 'justifications' produced by each dyad. Moreover, the number of speech acts linked in the appropriate sequence (e.g. 'claim-why', 'why-justification' and 'claimwhy-justification') was also counted in the final session. No two- or three-part sequences were coded for Sessions 2 or 4 due to the involvement of the researcher in making appropriate links at these stages.

A second rater conducted a reliability check on $30 \%$ of the final day's transcripts, plus one-third of the direct coding from video recordings, with equal numbers of extracts taken from each of the experimental and control conditions. For identification of the separate speech acts from transcripts (Day 5), there was high agreement in all instances. 97\% agreement (Kappa $=0.94$ ) was found for 'claim' acts, 99\% (Kappa = 0.98) for 'why questions' and 98\% (Kappa =0.97) for 'justifications'. Percentage agreement was 100\% for both 'claim-why' and 'claim-why-justification' patterns, although the frequencies were too small for Kappa calculations. There was a 97\% agreement for 'why-justification' with Kappa $=0.93$. From the video recordings of Days 2 and 4 , the agreement for 'claim' was 93\% (Kappa =0.83), 99\% for 'why questions' (Kappa $=0.96)$ and 97\% for 'justifications' (Kappa $=0.94)$.

\section{Results}

\section{Total number of speech acts by dyads across conditions and sessions (days)}

A total of 1198 relevant speech acts were recorded across Days 2, 4 and 5 of the study. As Table 1 shows, the experimental group dyads produced almost twice as many of these speech acts as the control group across all sessions, a difference that was statistically significant $(t(20)=4.58, p<0.01)$. A difference approaching significance was also found for speech act $\mathrm{x}$ intervention day, $F(2,40)=2.98, p=$ 0.06 , reflecting the fact that the differences were most marked on Days 2 and 4.

Table 1 The total and dyadic mean of speech acts during days 2, 4 and 5 of the intervention period

\begin{tabular}{|c|c|c|c|c|c||}
\hline \multirow{2}{*}{ Day } & \multicolumn{2}{|c|}{$\begin{array}{c}\text { Control Group } \\
\mathbf{N}=\mathbf{1 1}\end{array}$} & \multicolumn{2}{c|}{$\begin{array}{c}\text { Expt. Group } \\
\text { N=11 }\end{array}$} & Total \\
\hline & Freq. & Mean & Freq. & Mean & \\
\hline 2 & 134 & 12.2 & 255 & 23.1 & 389 \\
\hline 4 & 165 & 15 & 287 & 26 & 452 \\
\hline 5 & 143 & 13 & 214 & 19.4 & 357 \\
\hline Total & 442 & & 756 & & 1198 \\
\hline
\end{tabular}

\section{Frequency of individual speech acts produced by dyads for conditions and days}

We turn now to the frequencies for each type of speech act produced across conditions and days, with Table 2 summarising the findings. 'Claim' was more characteristic of the control group in all sessions. Conversely, the production of 'why' questions and 'justifications' was greater in the experimental group, again 
Table 2 The frequency and dyad means (in brackets) of speech acts during Days 2, 4 and 5 of the intervention period, for both groups

\begin{tabular}{|c|c|c|c|c|}
\hline \multicolumn{5}{|c|}{ Control Group $(\mathrm{N}=11)$} \\
\hline & Day 2 & Day 4 & Day 5 & Total \\
\hline Claim & $121(11)$ & $140(12.7)$ & $137(12.4)$ & $398(36.2)$ \\
\hline Why & $1 \quad(0.09)$ & $5 \quad(0.45)$ & $1 \quad(0.09)$ & $7 \quad(0.64)$ \\
\hline Justn & $12(1.1)$ & $20(1.8)$ & $(0.45)$ & $37 \quad(3.4)$ \\
\hline TOTAL & 134 & 165 & 143 & 442 \\
\hline \multicolumn{5}{|c|}{ Expt. Group $(\mathrm{N}=11)$} \\
\hline & Day 2 & Day 4 & Day 5 & Total \\
\hline Claim & $65 \quad(5.9)$ & $82(7.4)$ & $121(11)$ & $268(24.4)$ \\
\hline Why & $57 \quad(5.2)$ & $38 \quad(3.4)$ & $50 \quad(4.5)$ & $145(13.2)$ \\
\hline Justn & $133(12.1)$ & $167(15.2)$ & $43 \quad(3.9)$ & $343(31.1)$ \\
\hline TOTAL & 255 & 287 & 214 & 756 \\
\hline
\end{tabular}

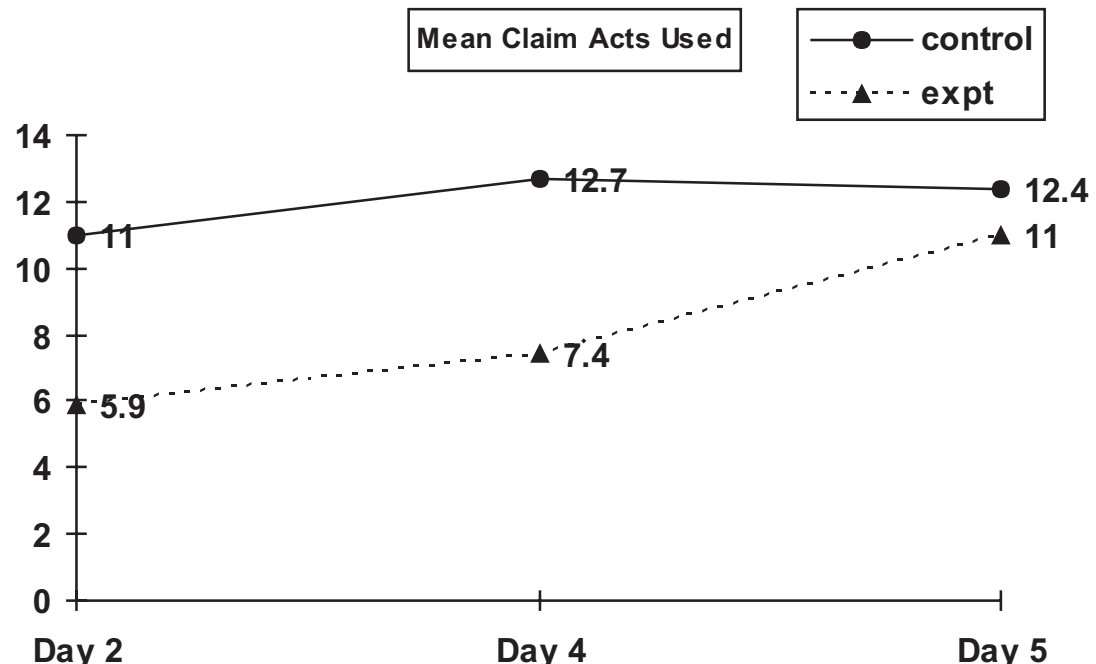

Figure 1 The dyadic mean number of claim acts across days and conditions

in all sessions. All types of speech acts peaked on Day 4 for the control group whereas there was a small dip in 'why' questions (Day 4) for the experimental group. A mixed three-way ANOVA (involving three levels of speech - claim, why, justification and two levels of condition - control and experimental, plus three levels of intervention day-Day 2, 4,5) indicated a significant difference for the main effect of speech act $[F(2,40)=59.2, p<0.001]$. Tukey post-hoc tests indicated that 'claim' was generally more frequent than the other two speech acts. There was also a significant interaction for condition $x$ type of speech act as $F(2$, $40)=43.16, p<0.001$, with 'claim' being used less in the experimental condition and 'why' and 'justification' being used more; but vice-versa in the control group. Post-hoc tests showed that the greatest source of variation across condi- 


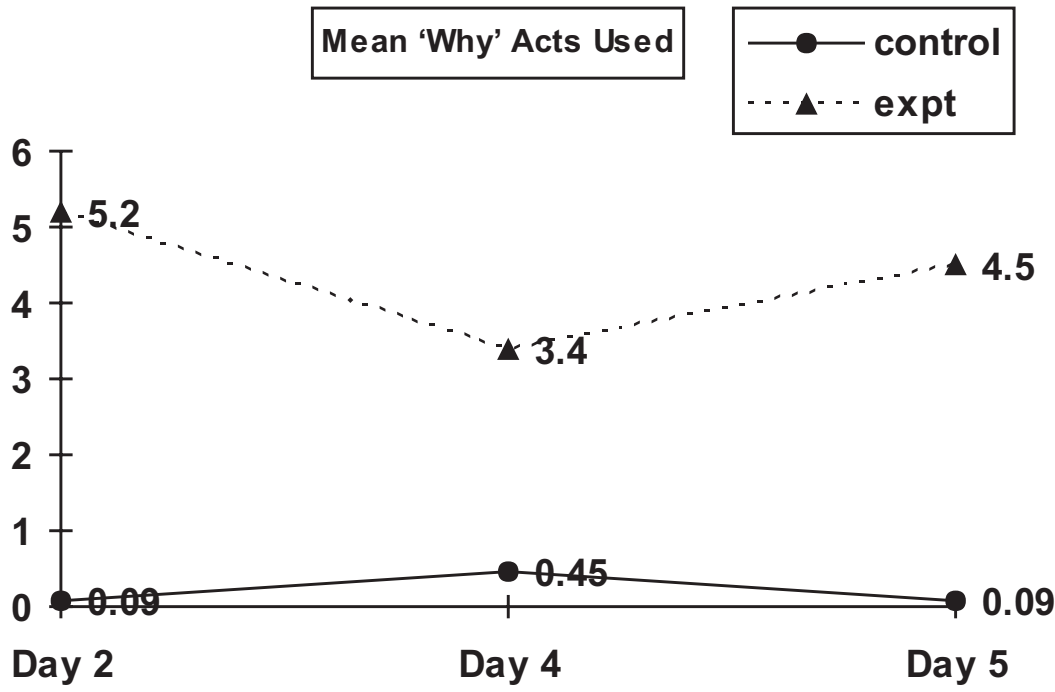

Figure 2 The dyadic mean number of 'why' acts across days and conditions

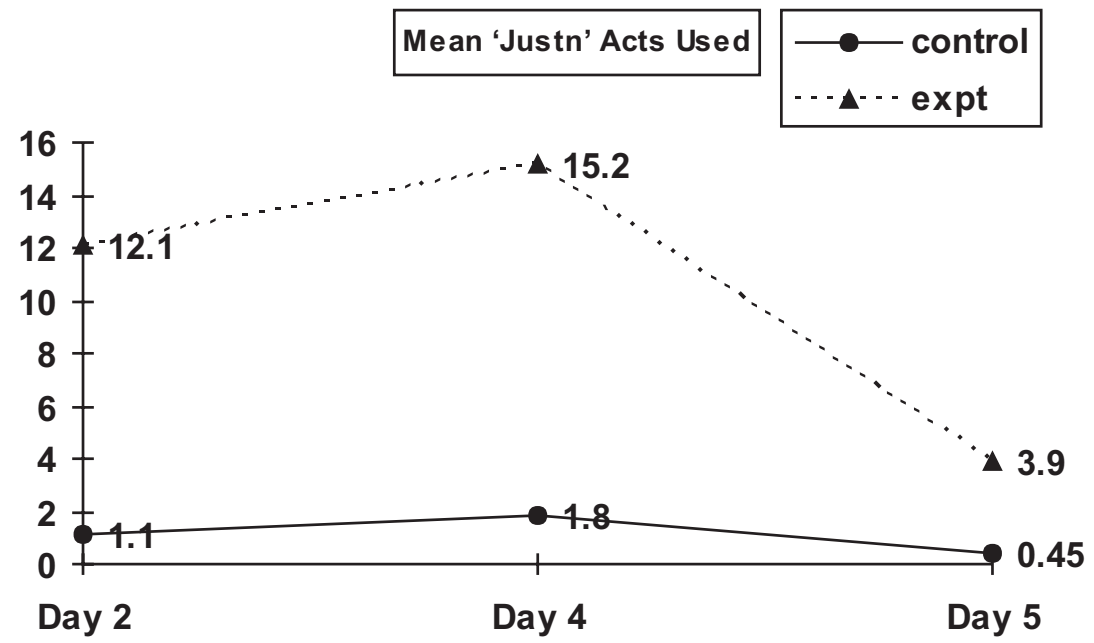

Figure 3 The dyadic mean number of 'justification' acts across days and conditions

tions was in relation to 'justification', with a smaller albeit still significant difference for both 'why' and then 'claim' tactics. In addition, there was a significant interaction effect found for type of speech act $\mathrm{x}$ intervention day with $F(4,80)=$ $9.79, p<0.01$ and an interaction effect between condition $x$ type speech act $x$ intervention day, $F(4,80)=6.33, p<0.001$. Post-hoc tests indicated that the control groups used significantly more 'claims' on Days 2 and 4 but not on Day 5 (see Figure 1). 
Tukey follow-up tests also indicated that the main source of variance across conditions in relation to 'why' questions occurred on Day 2. Furthermore, there was a smaller but significant variation for both Days 5 and 4 respectively (see Figure 2).

Finally, 'justification' strategies produced per day were analysed with regard to condition. Post-hoc tests showed that 'justification' use varied significantly for each of the three days across conditions, with the difference being greatest for Day 4 and smallest for Day 5 (see Figure 3). Although Tukey tests revealed that there was a significant variation between the supported sessions (Days 2 and 4) and the unsupported session (Day 5) of the experimental group, the smaller difference was still significant, thereby indicating that the effects of the intervention were being sustained.

Thus far, the results demonstrate that the dyads in the experimental group produced significantly more 'why' questions and 'justifications' at every stage of the intervention programme. The differences are illustrated qualitatively:

\section{Control condition}

(14) JA: I'm playing with that (yellow puppet).

TO: Do you not want to help with this?

JA: Yes, that's his nose and put his hair on.

\section{Experimental condition}

(15) KS: I've got the spaceship.

AM: Why've you got the spaceship?

KS: 'cos I want to fly away.

(16) CH: I've a broken spaceship.

SA: Why did the spaceship crash?

CH: Because he wasn't a very good driver.

These examples illustrate that the control group followed 'claims' with relatively simple questions and responses whereas the experimental condition produced more explanatory dialogue. They also show that the pre-schoolers are capable of linking the speech acts in the required sequences.

\section{Frequencies of linked speech sequences}

When the frequencies were gathered from the final session for two-turn sequences, it was found that 'claim' followed by 'why' questions occurred very rarely, with only one instance in the experimental group and none in the control group. For 'why-justification', there was one example in the control condition and 21 in the experimental group with $F(1,20)=4.44, p<0.05$. For three-turn sequences of 'claim-why-justification', there were no examples in the control group but four in the experimental group. Further evidence from the transcripts revealed that 'claim-other-justification' sequences were rare in both conditions.

In sum, it appears that the intervention was very successful in enhancing the production of individual justificatory speech acts, as shown by the greater frequencies of the experimental condition in all three sessions. It is worth reiterating that this means that the effects were successfully sustained in the unsupported 
session. However, the intervention was less effective in encouraging the children to link some of the speech acts, specifically 'claim-why' and 'claim-whyjustification' sequences.

\section{Discussion}

The central aim of the study was to design and evaluate an intervention programme that scaffolded justificatory dialogue in a personally meaningful context. The results show that, in general, the programme succeeded.

\section{The efficacy of the intervention procedure}

The results showed that the experimental group produced almost twice the number of relevant speech acts that the control group did. Although this was true for all sessions, it is worth noting that the number of speech acts peaked on Day 4 for both groups, possibly due to greater familiarity with the task and between participants. Alternatively, or in addition, it may be due to the extra, novel play materials which had been added, leading to more involved exchanges (e.g. Smilansky, 1968; Verba, 1993). The inclusion of a third puppet plus spaceship led to an expansion in play roles and themes, resulting in exchanges like the following:

(17) GR: I've crashed the spaceship.

LE: But why did it go bang?

GR: Dunno.

Res: Ask Spid why it crashed?

LE: Why did it go bang Spid?

GR: You know (points to researcher).

Res: Because it hit the ground very hard.

GR: Yeah ... and 'cos Spid's a bad driver.

LE: And ...' $\cos$ he's a monster.

To further assess the success of the intervention, the relative frequencies of each individual speech act used across conditions and sessions were examined. Ideally, one would expect approximately similar numbers of 'claims', 'why' questions and 'justifications' since these were modelled as a three-part sequence to the experimental group and, of course, exist naturally together in everyday life. However, only the unsupported session on Day 5 gives an accurate indication of this, since researcher input (which was not included in the data) played a substantial part in promoting, maintaining or elaborating sequences during earlier sessions.

Claim use was more frequent in the control group and remained consistently high across all sessions, but was most prevalent in the experimental group's unsupported session. These findings generally concur with data reported by McWilliam (1999), whereby 'claim' was the most predominant speech act by pre-schoolers during non-conflictual peer exchanges. The importance of 'claim' in pre-schoolers' discourse is further demonstrated by the spontaneous increase in 'claim' production by the experimental group in their unsupported session (despite similar increases in 'why' questions on Day 5), taking it closer to the level of 'claim' used by the dyads in the control condition. Given the normally high frequency of 'claim' used by nursery-school children (e.g. McTear, 1985), the 
anomaly here seems to be the lower number of 'claim' acts produced by the experimental group during the supported sessions. This may have arisen because the children expended most energy on using the less familiar justificatory sequences - especially as the researcher was quick to praise the production of these acts.

The results showed that justificatory speech was used infrequently by the control group, as expected. This is consistent with the view that pre-school children appear to be poor at reasoning in non-conflict situations (e.g. Baines, 1996; Cazden, 1986; Cooper \& Cooper, 1984). However, one should be wary of attributing this solely to biological immaturity because other factors tend to have a part to play (e.g. Donaldson, 1978). Indeed, it could be argued that the lack of direct, relevant experience was a factor in the control group's poor demonstration of reasoning skills. This is also borne out by the experimental group's superior performance, in producing 'why' questions and 'justifications' in a co-operative context across all sessions, relative to the control group.

Nevertheless, the findings for the experimental group are not straightforward. As expected, this group produced significantly more justifications than the control group across all sessions. Although the differences are greater for the supported than the unsupported sessions, this generally concurs with the proposal that 'why' questions and 'justifications' are more likely to occur in the presence of an adult (Barnes, 1976; Beal \& Flavell, 1982; Vespo et al., 1995; Webb, 1989) and it may also go some way to explaining the dip in 'justification' produced by the experimental group on Day 5 .

However, this does not explain the decrease in 'why' questions on Day 4. Interestingly, the lower production of 'why' questions on Day 4 occurred concurrently with the highest production of justications. This might be explained in relation to researcher input. To illustrate: one child sometimes made statements which were not followed up by the other child. The researcher would then encourage this child to ask 'why' - but, often, this child would leap ahead and answer the question posed by the researcher instead of repeating it, e.g:

(18) CH: They are friendly aliens.

SA: (No response)

Res: Ask why they are friendly.

SA: 'cos they don't hurt us.

Since language data were collected only for the pre-schoolers, this would lead to an imbalance between 'why' questions and 'justifications' particularly on Day 4 when the children tended to produce more dialogue overall. Lack of researcher links might also explain why there were almost equal numbers of these two main speech acts on the unsupported day. An example containing child-linked explanatory discourse is given below:

(19) GR: I've crashed the spaceship.

LE: But why did it crash?

GR: 'cos it falled.

LE: 'cos he wasn't a very good driver.

GR: He's crashed again!

LE: Why did he crash again? 
GR: 'cos he was so excited about going to hospital.

The above discourse provides an example of an important function of the intervention programme - the linking of individual speech acts into appropriate twoand three-part sequences. Hence the efficacy of the intervention can also be judged by examining the numbers of relevant sequences produced in each condition during the unsupported session. Some of the sequences (e.g. 'claim-why') occurred so infrequently that comparison of the conditions was meaningless. Nevertheless, the results for 'why-justification' sequences were promising, with one example in the control group but 21 in the experimental group. This difference was statistically significant. Comparing this with the infrequent links involving 'claim', it appears that children find it easier to make the 'why-justification' association. It could be that they have more knowledge and experience of this sequence because parents and teachers often use it (Orsolini, 1993). Furthermore, children may find it pointless to ask a 'why' question after a 'claim' since many of these statements accompany ongoing action and are self-explanatory. Children, like adults, tend not to question the obvious, e.g:

(20) CO: I'm flying the spaceship (child is moving it through the air).

AB: $\mathrm{Mmm}$.

On the other hand, if a 'claim' is totally false or exaggerated, young children may still not ask 'why' - preferring instead to oppose the statement, e.g:

(21) DA: My name's Toby.

AD: Your name's not Toby ... you stupid!

Similarly, 'claim' can also involve a degree of one-upmanship, as shown below:

(22) EM: Aghh ... he's biting my finger.

SH: Well ... he's biting MY HAND.

Additionally, asking 'why' after a 'claim' (especially of an adult) may appear somewhat challenging or even impudent, e.g:

(23) Teacher: I want you to tidy up.

Pupil: Why?

Understandably, given the rare examples of 'claim-why' sequences, the frequencies of three-turn 'claim-why-justification' patterns were also low. Lack of exposure to the relevant two-part sequences would make it more difficult for a child to integrate these into the corresponding three-part exchange. As the pattern of speech given in example 23 is unlikely to be encouraged by adults, it may be predicted that this type of exchange would diminish rather than develop due to a lack of positive reinforcement. Of course, there is an alternative explanation that the pre-schoolers might be unwilling rather than unable to produce these speech patterns frequently.

Finally, it is important to have some indication of the children's perceived understanding of what was involved in the intervention. The following extracts demonstrate to what extent the child pairs appeared to grasp the issues involved and were not only relying on simple repetition or mimicry: 
(24) JO: Hello.

SC: Hello.

JO: We've got to teach them to speak.

SC: Hello.

JO: They're not speaking to us.

SC: Don't say that ... what is your name ... Spid?

(25) NA: Why are you here?

EF: Because I want to speak English.

(26) DN: That one's mine ... that one's the lassie.

HU: I know.

DN: Let's make them talk.

HU: Hello ... I want to speak English.

(27) SH: What's that?

EM: It's Zag ... asking some questions.

SH: Right, you do it as well.

\section{Practical Implications of the Findings}

It can be concluded therefore that the intervention programme was successful in encouraging pre-school children to produce and use justificatory discourse during peer interaction. Furthermore, by looking at unsupported sessions as well as supported, it was clear that the beneficial effects were sustainable even without adult assistance. This was especially encouraging given the brevity of the intervention. Indeed, it is not unusual for researchers involved in the development of language skills to implement intervention programmes with longer sessions or an increased number of sessions (e.g. Cole, 1986; King \& Rosenshine, 1993; Palincsar, 1986), but this could be impractical for most educational interventions. It therefore appears that by tailoring the programme to the preschoolers' needs and interests, and by building on their resident abilities, the intervention produced the sought-after results in a short period of time.

Given the importance of language skills in educational curricula (e.g. Department for Education, 1995; Scottish Office Education Department, 1991; Strathclyde Regional Council's Education Department, 1994) and for efficient social interaction (e.g. Charlesworth, 1996; LaFreniere, 1996; Walker et al., 1994) as well as an association with more general socio-cognitive growth (e.g. Bruffee, 1984; Schober-Peterson \& Johnson, 1989), an intervention programme that effectively enhances the linguistic skills of pre-schoolers could be a worthwhile tool. This is especially true for children who appear to be particularly uninterested in or struggling with basic reasoning processes. The advantage of the present scheme is its flexibility, since the verbal schedules are arranged loosely around a theme of interest and children are encouraged to provide their own input within a supportive framework.

However, there are a number of specific issues which became apparent during the study that are relevant to practical application. The first was touched upon earlier, and relates to the difficulty that children may have in questioning claims made by adults. Since questioning may appear impudent or challenging (e.g. Extract 23), adults would be unlikely to encourage such sequences. Indeed, 
adults, and particularly teachers, may fear that children questioning their statements will lead to a breakdown in discipline in the classroom. Researchers such as Edwards and Westgate (1987), Forman and Cazden (1985), and Tizard and Hughes (1984), plus Fisher (1993), have commented upon the formality and constraints of the classroom, whilst Wegerif and Mercer (1996: 54) describe the student-teacher relationship as being 'asymmetrical'. Obviously this would make it extremely difficult for children to practise the questioning segment of the 'claim-why' sequence. Perhaps it would be possible for teachers or parents to set aside time for an activity understood by the children as acceptable to the adult, and giving them the chance to practise sequences of active listening, questioning and building on the responses.

The formality of the classroom has also been an issue when trying to evaluate young children's abilities from their observed performance. In fact, McTear (1985: 86) cautions that it would be 'misleading to classify children's speech as egocentric' as they might be unwilling to answer or have their attention diverted. Or, it might be that classroom time constraints and increasing teacher workloads do not provide the necessary time and conditions conducive to potentially emerging reasoning skills. Children who originally appear unable or unwilling to produce justificatory skills may just need the right atmosphere or encouragement to begin. This difficulty in distiguishing between perceived and actual ability is encapsulated in the following event from the present study, i.e.:

Two girls from the experimental condition had spent around nine minutes of the unsupported session without using any of the 'claim-why-justification' speech pattern. As it was nearing the end of their session the researcher, who was nearby but out of sight, came over to the girls and suggested that they end their play to enable the next dyad have access to the puppets. The girls protested, stating clearly that they had not yet helped the aliens speak English properly. They then proceeded to produce a stream of linked 'why-because' sentences based around earlier sessions, e.g.:

(28) CH: But we haven't said 'why' ... 'because'.

AM: Why have you got yellow hair.

$\mathrm{CH}$ : Because I've eaten too many bananas.

AM: And ... and why've you got a green nose?

$\mathrm{CH}$ : 'cos someone painted it in maybe ... and it got poison in it.

Thus it does appear that pre-school children are capable of producing appropriate justificatory speech, particularly after a degree of support. However, it can be argued that potential reasoning skills are not being given the full opportunity to develop within school settings. Yet one may suggest that the present results represent only a baseline of what can be achieved within a nursery school and, given the successful results of the intervention, this is very promising indeed for those interested in child education and development.

\section{Acknowledgements}

This study was originally reported in a doctoral thesis, written by the first author, whilst in receipt of an Economic and Social Research Council (ESRC) studentship. Both authors would therefore like to thank the ESRC for financial 
support. Thanks are also due to the technical staff within the psychology department and to Sheila Morrison, who assisted with reliability checks. Additionally, the authors wish to thank all the children and their parents, teachers and headteachers who were involved in the research. Finally, we would like to acknowledge the anonymous reviewers for comments and suggested minor revisions.

\section{Correspondence}

Any correspondence should be directed to Dr Donna McWilliam (donnamcwilliam@tiscali.co.uk).

\section{References}

Arsenio, W. and Lover, A. (1997) Emotions, conflicts and aggression during preschoolers' freeplay. British Journal of Developmental Psychology 15, 531-42.

Azmitia, M. (1988) Peer interaction and problem-solving: When are two heads better than one? Child Development 59, 87-96.

Baines, E. (1996) Discourse topic management and discussion skills of 4, 6 and 9 year olds: Developmental change, task and intervention effects. Unpublished PhD thesis, University of Strathclyde.

Barnes, D. (1976) From Communication to Curriculum. Harmondsworth: Penguin.

Beal, C. and Flavell, J. (1982) The effect of increasing the salience of message ambiguities on kindergartener's evaluation of communicative success and message adequacy. Developmental Psychology 18, 43-8.

Berkowitz, M.W., Gibbs, J.C. and Broughton, J. (1980) The relation of moral judgement disparity to developmental effects of peer dialogue. Merrill-Palmer Quarterly 26, 34157.

Bruffee, K. (1984) Collaborative learning and the 'conversation of mankind'. College English 46, 635-52.

Bruner, J.S. (1978) Berlyne memorial lecture. Acquiring the uses of language. Canadian Journal of Psychology 32, 204-18.

Calkins, S.D., Gill, K.L., Johnson, M.C. and Smith, C.L. (1999) Emotional reactivity and emotional regulation strategies as predictors of social behavior with peers during toddlerhood. Social Development 8, 310-34.

Cazden, C. (1986) Classroom discourse. In M. Wittrock (ed.) Handbook of Research on Teaching (pp. 423-65). New York: MacMillan.

Charlesworth, W. (1996) Cooperation and competition contributions to an evolutionary and developmental perspective. International Journal of Behavioural Development 19, 2539.

Cole, D. (1986) Facilitating play in children's peer relationships: Are we having fun yet? American Educational Research Journal 23, 201-15.

Cooper, C., Ayers-Lopez, S. and Marquis, A. (1982) Children's discourse during peer learning in experimental and naturalistic situations. Discourse Processes 5, 177-91.

Cooper, C. and Cooper, R. (1984) Skill in peer learning discourse: What develops? In S. Kurzak (ed.) Discourse Development 77-97. New York: Springer-Verlag.

Department for Education (1995) English in the National Curriculum. London: HMSO.

Donaldson, M. (1978) Children's Minds. London: Fontana.

Edwards, A. and Westgate, D. (1987) Investigating Classroom Talk. London: Falmer.

Eisenberg, A. and Garvey, C. (1981) Children's use of verbal strategies in resolving conflict. Discourse Processes 4, 149-70.

Fey, M.E. (1988) Generalisation issues facing language interventionalists: An introduction. Language, Speech and Hearing Services in Schools 19, 272-81.

Fisher, E. (1993) Distinctive features of pupil-pupil classroom talk and their relationship to learning: How discursive exploration might be encouraged. Language and Education $7(4), 239-57$. 
Forman, E. and Cazden, C. (1985) Exploring Vygotskian perspectives in education: The cognitive value of peer interaction. In J. Wertsch (ed.) Culture, Communication and Cognition: Vygotskian Perspectives (pp. 323-47). New York: Cambridge University Press.

Goncu, A. (1993) Development of intersubjectivity in social pretend play. Human Development 36, 185-98.

Howe, C.J. (1997) Gender and classroom interaction: A research review. Scottish Council for Research in Education, 138.

Howe, C.J. and McWilliam, D. (2001) Peer argument in educational settings: Variations due to socio-economic status, gender and activity context. Journal of Language and Social Psychology 20, 61-80. London: Sage

Howe, C.J., McWilliam, D., and Bermejo Bravo, F. (2000) Discussion Skills in Early Childhood: Peer Interaction During Disputes and Non-conflictual Play. Report prepared for the Scottish Executive.

Iskander, N., Laursen, B., Finkelstein, B. and Frederickson, L. (1995) Conflict resolution among preschool children: The appeal of negotiation in hypothetical disputes. Early Education and Development 6, 359-76.

Jensen, A. (1968) Social class and verbal learning. In M. Deutsch, I. Katz and A. Jensen (eds) Social Class, Race and Psychological Development (pp. 115-74). New York: Holt Rinehart and Winston.

King, A. and Rosenshine, B. (1993) Effects of guided co-operative questioning on children's knowledge construction. Journal of Experimental Education 61, 127-48.

Kirchner, D.M. (1991) Using verbal scaffolding to facilitate conversational participation and language acquisition in children with pervasive developmental disorders. Journal of Childhood Communication Disorders 14, 81-98.

Kruger, A.C. (1993) Peer collaboration: Conflict, co-operation, or both? Social Development 2, 165-82.

LaFreniere, P. (1996) Cooperation as a conditional strategy among peers: Influence of social ecology and kin relations. International Journal of Behavioural Development 19, 39 52.

Levy, A., Wolfgang, C. and Koorland, M. (1992) Sociodramatic play as a method for enhancing the language performance of kindergarten age students. Early Childhood Research Quarterly 7, 245-62.

Luce, G.G. (1973) Body Time: The Natural Rhythms of the Body. London. Paladin.

McGrew, W.C. (1972) Aspects of social development in nursery school children with emphasis on the introduction to the group. In N. Burton-Jones (ed.) Ethological Studies of Child Development. Cambridge. Cambridge University Press.

McTear, M.F. (1985) Children's Conversations. Oxford: Blackwell.

McWilliam, D. (1999) A study into the discussion skills of nursery school children. Unpublished PhD thesis, University of Strathclyde.

Meadows, S. (1986) Understanding Child Development. London: Routledge.

Mentis, M. (1994) Topic management in discourse: Assessment and intervention. In K. Butler (ed.) Topics in Language Disorders: Pragmatics and Social Skills in School-age Children and Adolescents 14, 29-54. Rockville, MD: Aspen.

O'Donnell, A. and Dansereau, D (1992) Scripted cooperation in student dyads: A method for analyzing and enhancing academic learning and performance. In $R$. Hertz-Lazarowitz and N. Miller (eds) Interaction in Cooperative Groups (pp. 120-41). Cambridge: Cambridge University Press.

Orsolini, M. (1993) Dwarfs do not shoot: An analysis of children's justifications. Cognition and Instruction 11, 281-97.

Palincsar, A.S. (1986) The role of dialogue in providing scaffolded instruction. Educational Psychologist 21, 73-98.

Piaget, J. (1926) The Language and Thought of the Child. London: Kegan Paul.

Read, B. and Cherry, L. (1978) Preschool children's production of directive forms. Discourse Processes 1, 233-45.

Schober-Peterson, D. and Johnson, C. (1989) Conversational topics of 4 year olds. Journal of Speech and Hearing Research 32, 857-70. 
Scottish Office Education Department (1991) English Language 5-14. Edinburgh: HMSO. Smilansky, S. (1968) The Effects of Sociodramatic Play on Disadvantaged Preschool Children. New York: Wiley.

Strathclyde Regional Council Education Department (1994) Partners in Learning: 0-5 Curriculum Guidelines. Glasgow: Strathclyde Regional Council.

Swiezy, N., Matson, J. and Box, P. (1992) The good behaviour game - a token reinforcement system for preschoolers. Child and Family Behaviour Therapy 14, 21-32.

Tizard, B. and Hughes, M. (1984) Young Children Learning. London: Fontana.

Tolmie, A. and Howe, C.J. (1993) Gender and dialogue in secondary school physics. Gender and Education 5, 191-209.

Verba, M. (1993) Co-operative formats in pretend play among young children. In C. Pontecorvo (ed.) Cognition and Instruction: Discourse and Shared Reasoning 11, 265-80. Hillsdale, NJ: Lawrence Erlbaum.

Vespo, J., Pedersen, J. and Hay, D. (1995) Young children's conflicts with peers and siblings: Gender effects. Child Study Journal 25, 189-212.

Vygotsky, L.S. (1962) Thought and Language. Cambridge: MIT.

Walker, H., Schwarz, I., Nippold, M., Irvin, L. and Noell, J. (1994) Social skills in school-age and youth: Issues and best practices in assessment and intervention. In K. Butler (ed.) Topics in Language Disorders: Pragmatics and Social Skills in School-age Children and Adolescents 14, 70-82.

Webb, N. (1982) Group composition, group interaction and achievement in co-operative small groups. Journal of Educational Psychology 74, 475-84.

Webb, N. (1989) Peer interaction and learning in small groups. International Journal of Educational Research 13, 21-39.

Wegerif, R. and Mercer, N. (1996) Computers and reasoning through talk in the classroom. Language and Education 47-64. 